\title{
The Missouri Developmental Disability Resource Center: A Web site responding to the critical need for information of parents with a child with a disability
}

\author{
RICARD E. DOWNING, TANYA D. WHITEHEAD, LISA TERRE, and CARL F. CALKINS \\ University of Missouri, Kansas City, Missouri
}

\begin{abstract}
One of the greatest problems for parents who have a child with a developmental disability is a lack of access to information. Parents have a critical need to learn the specifics of their child's disability, the best treatment practices, and how the broader service delivery system works (Bradley, 1992; Rinck, Calkins, Green, \& Stadler, 1986). The Missouri Developmental Disabilities Resource Center Web site [http://www.moddrc.com] was created as an innovative method of meeting the information needs of this underserved population. Challenges to the adoption of this innovative model are highlighted, and some options for addressing these issues are discussed.
\end{abstract}

Technology is a design for instrumental action that reduces the uncertainty in the cause-effect relationships involved in achieving a desired outcome. (Rogers, 1995, p. 12)

In the 1980s and $1990 \mathrm{~s}$, the special concerns of families of people with disabilities emerged as a central issue in the broader national policy debate on developmental disabilities (Knoll, Covert, Osuch, O'Connor, Agosta, \& Blaney, 1992). As early as 1979 , Skarnulis called for policymakers to stop supplanting the family and start supporting it. In addition, the importance of governmentsubsidized family supports, as well as more informal helping networks, was emphasized heavily in the last two presidential elections. As a result, a policy of family support has evolved to help keep children and their families together. Often labeled family-centered planning or family empowerment (Bradley, Ashbaugh, \& Blaney, 1994), these policies focus on helping families experience the quality of life enjoyed by those families who do not have a member with a disability (Agosta, Bradley, \& Knoll, 1992). In the last 2 years, family-directed support legislation has become a high priority nationally and at the state level.

Knoll, Covert, and colleagues contend that these developments require "efforts to re-examine and redefine the relationship between the public sector and families of

R.E.D. received the Castellan Student Award for his work on this study The Web site described in this study is supported by a grant from the Missouri Planning Council. The authors thank David Rinck and Chad Hurt for assistance. Correspondence concerning this article should be addressed to R. E. Downing, University of Missouri, 2220 Holmes, Room 129, Health Sciences Building, Kansas City, MO 64108 (e-mail: downingr@umkc.edu). children and adults with disabilities and between such families and informal helping networks" (Knoll et al., 1992, p. 57). Stimulated by changes in the political and economic climate, family-centered planning is gaining momentum as a major trend in home-based services for people with developmental disabilities (Knoll et al., 1992).

However, family-centered planning has yet to be fully realized. Few families who have a child with a developmental disability have experienced ideal family support (Bradley, 1992; Knoll et al., 1992). Instead, families report experiencing an uncoordinated, often confusing, system of public, private, and helping network supports for the home and specialized healthcare needs of children with disabilities (Knoll, 1992). In addition, parents do not know enough about particular disabilities, best practices, or how the state system works in terms of available services for developmental disabilities (Bradley, 1992; Rinck, Calkins, Green, \& Stadler, 1986; Rinck \& Eddy, 1988). Information that is available is sparse, hard to find, incomplete, and often outdated (Rinck et al., 1986). In short, parents need more information about (1) the nature of their child's problem, (2) what is known about the disability, (3) how to best help their child, (4) what the experts recommend, (5) how to access the services and supports needed, and (6) how all the systems interact (Whitehead, 1998).

The University of Missouri-Kansas City Institute for Human Development-University Affiliated Program, with funding from the Administration on Developmental Disabilities, addresses these problems faced by Missouri families. As one component of a larger information dissemination plan, the Institute began research and development on alternative formats for information exchange. 
This study describes one such alternative format, the Internet Web site. Based on diffusion of innovation theory (Rogers, 1995), the Missouri Developmental Disability Resource Center [http:// www.moddrc.com] is designed to offer a comprehensive, systematically organized source of information that is available to the parents of children with developmental disabilities, professionals, caregivers, and other interested parties. Funded by a grant from the Missouri Planning Council for Developmental Disabilities, the Web site is an attempt to centralize information about state resources, programs, and agencies, helping networks in the patron's community, professional resources, and current research regarding developmental disabilities. Furthermore, it is hoped that the Web site may be useful as a model for the development of Web sites related to the delivery of psychologyrelated resources. Special attention is given to promoting adoption by the intended audience.

Much of the work surrounding the creation of this Web site has been guided by Rogers' (1995) diffusion of innovation theory. From Rogers' view, 'the innovationdevelopment process usually begins with recognition of a problem or need, which stimulates research and development activities designed to create an innovation to solve the problem or need" (Rogers, 1995, p. 132). Hence, innovation and its diffusion must be considered a social process in which participants communicate their personal perceptions about a new idea with others. In other words, diffusion is facilitated to the extent that participants exchange creative ideas to reach common ground (Ditcoff, 1998; Rogers, 1995).

In support of Rogers' (1995) model, research has shown that personal perception is one of the most important predictors of innovation adoption in a wide variety of disciplines, including computer-based learning (e.g., Surry \& Gustafson, 1994) and preventive health innovations (e.g., Meyer, Johnson, \& Ethington, 1997; Miller, Klotz, \& Eckholdt, 1998). The data suggest that this finding applies across a range of study participants, encompassing diverse developmental levels and occupational groups.

Because the personal perception of an innovation by adopters is so critical to its adoption, the Missouri Developmental Disabilities Resource Center Web site designers determined to first create the site and then solicit feedback from a parent advisory committee, to better understand how to improve the site to more readily meet their needs. Parent involvement in designing the site at the outset encouraged their adoption of the site as it developed. Designers also used the same approach with professionals. On the basis of group meetings, professionals suggested that the site should contain a current research library on developmental disabilities. As with parents, the more professionals helped design the site, the more adopters the site developed in the professional community. In short, consistent with Rogers' (1995) emphasis on learning by doing, the Web site was designed to encourage its intended users to learn by using the site. Because learning by doing is a two-way street, patrons learned how to use the site by trying it, and designers learned to improve the design of the site by making changes the users recommended. This reciprocal relationship both improved the site design and assisted in the diffusion of the innovation across the community. The Web site development has been analogous to the case in which architects who design and build a new university campus purposely leave out the sidewalks. Later, the architects return and build sidewalks where students have worn paths between the buildings. Hence, the users of the access routes determine the best approach to the available resources (Schwartz, 1992).

\section{DESIGN PERSPECTIVE}

It is expected that the most common patron of the site will be the parent of a child with a disability. On the basis of preliminary experiences, parent users will have a high level of interest and will be operating under conditions of stress. They will be seeking assistance in a straightforward manner. For this reason, every effort was made to facilitate access and to provide easily understood paths to information and clear instructions for use. Although the Web site initially evolved using widely accepted development practices (consistent backgrounds, text fonts/ sizes, buttons, etc.), after much collaboration with professionals and families with children with disabilities, the site was changed to be more colorful, inviting, and accessible to its patrons.

The site is currently undergoing a page-by-page accessibility test that will ensure compliance with Bobby (for a review, see Axelson, 1998). Bobby is a free service of $\mathrm{CAST}^{1}$ (Center for Applied Special Technology, Peabody, MA) that will analyze single Web pages for their accessibility to people with disabilities (for more information, see Disability Access Resources, on line ${ }^{2}$ ). Bobby also incorporates the new universal design (UD) guidelines, established by the World-Wide Web Consortium Web Accessibility Initiative (W3C's WAI), ${ }^{3}$ on accepted standards for accessibility of Web sites.

This site was designed with industry standard applications such as Microsoft FrontPage Web page/site development software, Adobe PhotoShop graphic software, and Adobe Pagemill Web page/site development software. It was the intention of the developers to create a Web site that Institute personnel could maintain, rather than one requiring highly trained, highly skilled, and expensive computing experts to perform day-to-day maintenance. Any change or addition to the site is made by using the standard (or included) capabilities of the development programs described above. Customization is thus limited, and anyone who has been trained in the use of these industry standard packages can immediately begin maintaining the site.

Web-Board conferencing software has been included in the design of the site. This software offers bulletin board service, listserv capabilities, and chat rooms. The 
software was chosen because it offers swift, reliable addition of new conference areas, provides both closed and open conference areas, and allows for recording of chat sessions for later download by patrons who were unable to attend specific chat sessions. Closed conferences are those that require a moderator to add new users (e.g., for restricted use by a committee or consortium). Open conference areas are those that allow new users to join the conference on their own, with no registration required. The conference areas alone have had in excess of 22,000 visitors since the inception of the site.

\section{HARDWARE}

The Web site is hosted on an IBM Netfinity server. Maintenance of the site is accomplished from Dell Pentium II desktop PCs connected to the Netfinity server via an Ethernet local area network. The Netfinity server is connected to the university fiber backbone that provides access to the Internet.

\section{APPLICATION CHALLENGES}

As Rogers (1995) points out, innovation is not an event; rather, it is one step in a process culminating in the efficient dissemination and adoption of the innovation. The researchers are currently faced with application challenges surrounding the adoption of this innovative method of information dissemination. According to Rogers (e.g., 1995; Rogers \& Kincaid, 1981), the predominant barriers to adoption include the relative superiority of the innovation ("relative advantage"), the extent to which it is perceived to be consistent with users' values and needs ("compatibility"), difficulty of use ("complexity"), extent to which the innovation is "test driveable" ("trialability"), and extent to which the results are visible to others ("observability").

Very little research has directly examined Rogers' (1995) barriers to diffusion of innovation, and the few existing studies have yielded mixed results. Taken together, the current literature, although sparse, provides empirical support for at least some of the barriers proposed in the model, although different studies suggest that some barriers may be more important than others. For example, some work indicates that complexity (e.g., Martinez-Brawley, 1995; Meyer et al., 1997; Surry \& Gustafson, 1994; Wells \& Anderson, 1997), relative advantage (e.g., Howze \& Redman, 1992; Meyer et al., 1997; Surry \& Gustafson, 1994), and compatibility (e.g., Howze \& Redman, 1992; Martinez-Brawley, 1995; Meyer et al., 1997; Surry \& Gustafson, 1994; Wells \& Anderson, 1997) are particularly important to the adoption of innovation, whereas trialability and observability may have less relative impact on innovation acceptance (e.g., Meyer et al., 1997; Surry \& Gustafson, 1994).

For the purposes of this study, complexity involved user unfamiliarity with microcomputers, Internet service providers, and access to the Internet. In an effort to address these issues, text-based training manuals were developed, and specific training sessions were provided to groups of prospective users (e.g., parents, professionals, and others interested in developmental disabilities). In addition, a CD-ROM is being developed to train potential users in the skills required to access the Web site. Similar Web-based training is being developed simultaneously. A parent advisory committee made up of parents who have a child with a developmental disability has been established to help guide the development of the training.

Ease of use was emphasized in Web site construction, thereby lessening the complexity of the site and increasing the potential for more rapid adoption by the intended audience. Conference areas on the Web site that are easily accessible to patrons are often used to answer questions regarding certain technical aspects of the site. The small group meetings and question and answer sessions served to mitigate concerns and trepidation about the Web site. However, because many potential adopters do not have a computer available, researchers have endeavored to provide donated, used computers to some potential adopters. In addition, public access computers are widely available at public libraries, community colleges, and other state-affiliated facilities throughout the state. The locations of these public access computers have been compiled, and the list is available free to anyone who asks for it, simply by dialing an 800 number. ${ }^{4}$ Callers can also request information on the specific location of public access computers closest to their homes. Specific recommendations regarding microcomputer capabilities are made to those individuals considering the purchase of a computer for their home use. It should be noted that no specific computer manufacturer or sales agency is ever recommended - only capabilities. Most major computer manufacturers easily meet these capabilities.

Focus groups of professionals who work with families with a child with a developmental disability were arranged. Feedback from this group of professionals was gathered, and appropriate changes were made to accommodate their recommendations. Recommendations to date include adding a current research section to the site that will act as a repository with links to the latest research regarding developmental disabilities.

Consensus meetings were held involving state organizations within the Division of Mental Retardation and Developmental Disabilities, local members of Psi Chi (national honor society for psychology), and helping network leaders, professors, teachers, and school principals. Training sessions were established at 11 regional centers of the Missouri Department of Mental Health offices throughout the state, and shortcuts to the site were placed on the Microsoft Windows 95 desktop, for easy access to the site.

Question and answer sessions have been useful in demonstrating that the site offers an improvement over existing information sources (i.e., relative advantage). Organizers of the sessions state that potential patrons seem to feel more comfortable after having their questions answered. We are currently in the process of devel- 
oping a formal, systematic evaluation of perceptions regarding comfort with the technology (i.e., compatibility).

\section{SITE CONTENT}

The Developmental Disabilities Resource Center is a comprehensive Web site that organizes disparate information on disabilities and provides patrons with a single source for access to national support directories, resource packets, reports of school district projects, best treatment practices, and conference rooms. The complete site map is depicted in Figure 1.

\section{Information About Disabilities}

The Web site provides a number of links to related sites that furnish general information regarding agencies involved in providing information and/or services to families of individuals with a developmental disability. Some sample links include People First of Kansas City, the Missouri Planning Council, the American Association on Mental Retardation, and the American Association of University Programs.

Resource packets regarding specific disabilities. Packets on 87 disability-related topics (e.g., the Americans with Disabilities Act, family support, financial aid, educational assessments, fitness and developmental disabilities) and 100 specific disabilities (e.g., aphasia, apraxia, autism, Jakob-Creutzfeldt syndrome) are available from the site. The patron may request up to five of these packets at a time. The packets are currently sent via regular U.S. mail. Future site enhancements will allow the patron to print or order the packets directly from the site. As is shown in Table 1, the site has seen an increase in the number of packet requests.

In addition to an increase in the total number of requests, the source of the requests has changed over time. Although initially more professionals asked for packets, over the last year parent requests are beginning to outnumber those by professionals. Subject to confirmation by additional research, we hypothesize that at least some of this change may be attributable to our increased efforts to directly liaison with parent groups, to professional dissemination of Web site information to constituents, as well as to networking among parents who have found the site helpful.

On-line information. This area of the site provides patrons with specific information of special relevance to families who have a member with a disability. Examples include discussions of how to navigate the system when their child has special needs, program planning for older persons with developmental disabilities, and community inclusion.

\section{Information About Support}

National support directories. A number of national helping networks and organizations (e.g., the National Spinal Cord Injury Association, the American Society for Deaf Children, the American Foundation for the
Blind) have Web sites. Links to these sites have been established, and familiarization sessions have been planned with many of these organizations. This part of the site is one of the most rapidly expanding areas in the site.

Support. Conference rooms that offer chat and listserve capabilities by classification or support structure are provided. Classifications include employment information for people with developmental disabilities (including hints and tips for obtaining employment), information regarding the Missouri Department of Mental Health Division of Mental Retardation and Developmental Disabilities family-directed support program (planned), and a conference area for parents of children with developmental disabilities to share ideas and support, as well as a number of other conference areas.

Reports. Full-text reports are available at the site, describing more than 20 ongoing, school-based programs for people with developmental disabilities. Among the listed projects are those that focus on youth career options, job and life skill development, actual job training in the classroom, and supervised job placement at work sites. More reports will be added to the site as they become available.

\section{Information About Best Practices}

For the present purposes, the term best practices refers to professional standards of practice based on current empirical data and professional consensus (e.g., Oss, 1998). Given that one of our goals is to make recent advances in the field of developmental disability easily available to users, the site contains a listing of articles describing some best practices in selected areas (e.g., transitioning from traditional to person-centered planning, suggestions for positive behavior supports for children engaged in challenging behaviors). Clearly, professional acceptance of different practices shifts with innovations resulting from research, practice, and emerging systems of healthcare (Oss, 1998). For this reason, we plan to review and, where needed, update this part of the Web site on a regular basis.

\section{Future Enhancements}

Challenges do not end with the development of an innovative Web site. Instead, diffusion of the innovation and maintenance of innovativeness become key to the ongoing success of the site. One planned enhancement is "Home of My Own," a conference area for resources and discussions on owning or renting a residence. As interest grows in this aspect of the site, links will be provided to real estate agents and apartment managers who are willing to work with people with developmental disabilities. Hints and tips for maintaining one's residence will also be available. Specific experiences of people with developmental disabilities in regard to living independently and any special supports required to carry out dayto-day activities will be highlighted. Another planned enhancement is the addition of training courses primarily directed at computer and Internet use (e.g., Web-based 


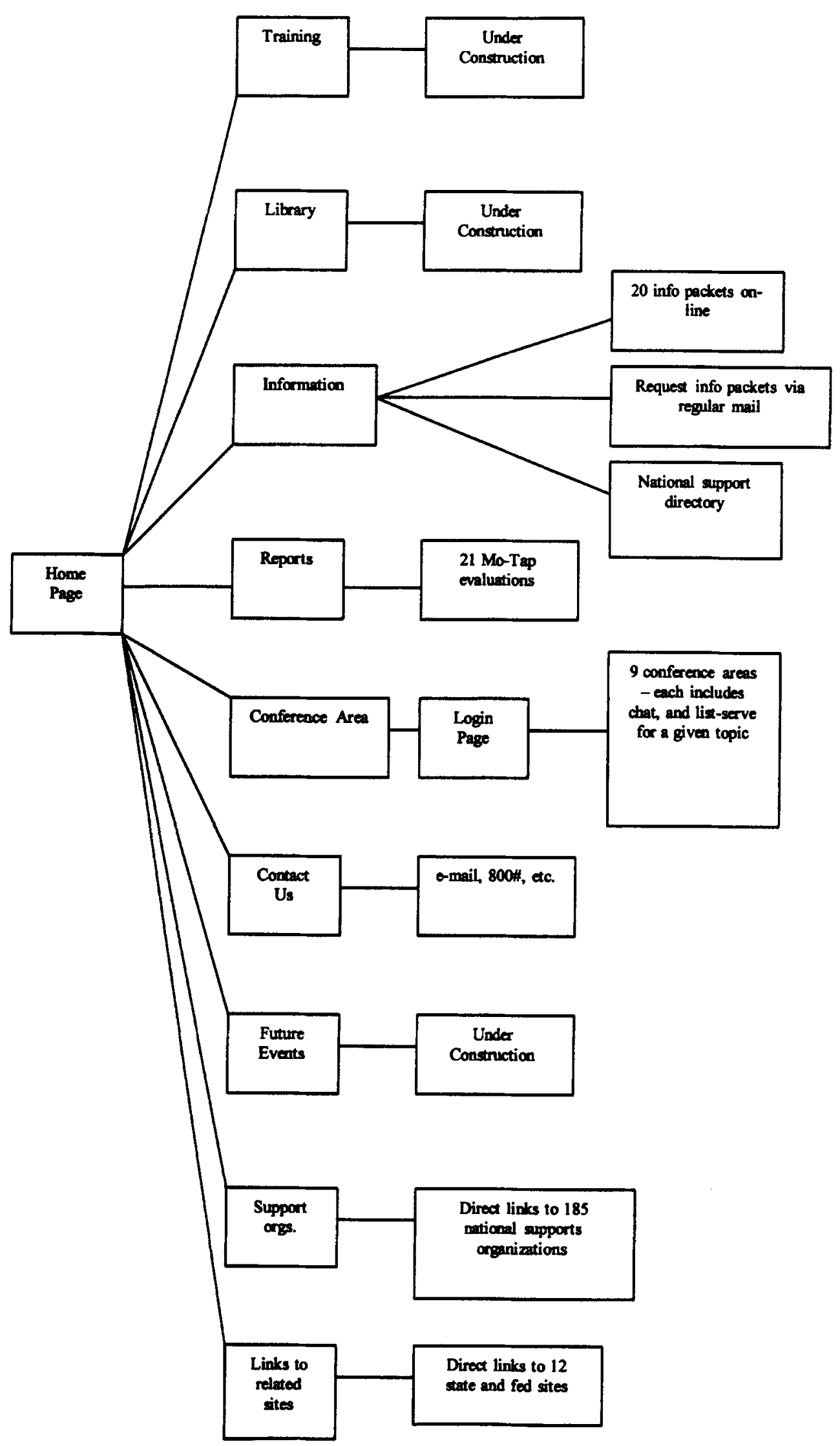

Figure 1. Site Map for Developmental Disability Resource Center. 
Table 1

Packet Requests by Year

\begin{tabular}{lc}
\hline Year & $\begin{array}{c}\text { Number of Packets } \\
\text { Requested }\end{array}$ \\
\hline 1996 & 436 \\
1997 & 1,860 \\
1998 (Oct., Nov., Dec.) & 977 \\
\hline
\end{tabular}

Note-Years are based on a fiscal year as determined by the Missouri Planning Council from October 1 through September 30. Packet requests for 1998 represent those received in the first quarter of fiscal $1998 / 1999$

training, computer-based instruction, CD-ROM training). A number of other enhancements are in varying stages of development.

\section{DISCUSSION}

Our experiences with the Missouri Developmental Disabilities Resource Center demonstrate that it is possible to develop a relatively low cost, systematically organized venue for information dissemination that responds to the needs of professionals, families, and caregivers of individuals with a developmental disability. The Web site has been well received by users, and many community partners have expressed interest in disseminating their materials via the site.

Perhaps the uniqueness of the Web site lies in the fact that it has been developed and is maintained using widely accepted industry standard software that has been integrated tightly and coupled with existing Institute and university standard hardware and connectivity infrastructure. No special computing expertise is required to maintain or change the functionality of the site. The site can be easily expanded to meet new requirements of patrons. Institute personnel, who have had some minimal training in the use of the software packages employed to maintain the site, can easily add new features. At a time when highly trained, experienced computing professionals are in short supply, this capability offers a decided advantage. Because of this easy adaptability, the site offers current information regarding the status of services available to families who have a child with a developmental disability. The need for current information regarding family support structures is a high priority for these families (Knoll et al., 1992).

The site also helps to unify and organize the often bewildering array of state support services for people with developmental disabilities. Furthermore, it holds promise for providing an avenue for interagency collaboration regarding state financial commitments to family support. In some instances, families may technically be eligible for assistance from several agencies simultaneously. It is our hope that the site will be instrumental in the formation of a comprehensive overview of state services available for support to families with a developmental disability and will serve to inform developers of similar sites.
Going forward, the site will provide much needed data regarding patron demographics, utilization, and dissemination patterns and rates. This information may prove useful in the development of new services offered by the state and, of course, of new features of the site. Currently, we are developing measurement instruments to be used in the collection of data regarding potential adopters' perceptions of the site. Now that the initial stages of implementation have been completed, we plan to systematically examine the diffusion of this innovation. For example, as the site becomes more widely advertised and used, research will be conducted on the relative impact of Rogers' (1995) proposed barriers. Additional studies are planned to help direct future enhancements to the site, including specific training requirements of potential adopters, as well as the study of early adopters, and their effect on dissemination of the technology.

There are, of course, other Web sites that provide much valuable information regarding specific aspects of developmental disabilities. However, the effort to consolidate such a wealth of up-to-date information regarding developmental disabilities at a single site and deliver this information to the people who need it most is rare. With Rogers' (1995) theory as a guide, this site may potentially change the way professionals, family members, and consumers of Missouri state services interact with each other and conduct business with providers of these services.

\section{REFERENCES}

Agosta, J., Bradley, V., \& KNOLl, J. (1992). Toward a positive family policy. Cambridge, MA: Human Services Research Institute.

AXELSON, M. (1998). Equal-opportunity access: Designing pages for people with disabilities [On-line]. Available: http://newmedia.com/ NewMedia/98/07/fastforward/Design_pages_Disabilities.html

BradLEY, V. J. (1992). Overview of the family support movement. In V. J. Bradley, J. Knoll, \& J. M. Agosta (Eds.), Emerging issues in family support 18 (pp. 1-8). Washington, DC: American Association on Mental Retardation.

Bradley, V. J., Ashbaugh, J. W., \& Blaney, B. C. (1994). Creating individual supports for people with developmental disabilities. Baltimore: Paul H. Brooks.

DitcoFf, M. (1998). 20 qualities of an innovator. Innovation Network: Articles \& Reports [On-line]. Available: http//www.innovating.com/ page_25.html

HowzE, E. H., \& Redman, L. J. (1992). The uses of theory in health advocacy: Policies and programs. Health Education Quarterly, 19, 369-383.

KNOLL, J. (1992). Being a family: The experience of raising a child with a disability or chronic illness. In V. J. Bradley, J. Knoll, \& J. M. Agosta (Eds.), Emerging issues in family support 18 (pp. 9-58). Washington, DC: American Association on Mental Retardation

Knoll, J., Covert, S., Osuch, R., O'Connor, S., Agosta, J., \& BlaneY, B. (1992). Supporting families: State family support efforts. In V. J. Bradley, J. Knoll, \& J. M. Agosta (Eds.), Emerging issues in family support 18 (pp. 57-97). Washington, DC: American Association on Mental Retardation.

Martinez-BraWley, E. (1995). Knowledge diffusion and transfer of technology: Conceptual premises and concrete steps for human service innovators. Social Work, 40, 670-682.

Meyer, M., Johnson, J. D., \& Ethington, C. (1997). Contrasting at- 
tributes of preventive health innovations. Journal of Communications, 47, 112-131.

MilLeR, R. L., KLOTZ, D., \& EcKholdt, H. M. (1998). HIV prevention with male prostitutes and patrons of hustler bars: Replication of an HIV preventive intervention. American Journal of Community Psychology, 26, 97-131.

Oss, M. (1998). What are "best practices" anyway? Behavioral Health Management, 18, 3 .

Rinck, C., Calkins, C. F., Green, J. W., \& Stadler, H. (1986). Family support services for the mentally retarded/developmentally disabled in Missouri. Unpublished manuscript, University of Missouri, Kansas City, Institute for Human Development.

RINCK, C., \& EDDY, B. (1988). Analysis of the purchase of service system of the Missouri Division of Mental Retardation and Developmental Disabilities. Unpublished manuscript, University of Missouri, Kansas City, Institute for Human Development.

Rogers, E. M. (1995). Diffusion of innovations (4th ed.). New York: Simon \& Schuster.

Rogers, E. M., \& KINCAID, D. L. (1981). Communication networks: Toward a new paradigm for research. New York: Free Press.

SCHWARTz, D. (1992). Crossing the river: Creating a conceptual revolution in community and disability. Cambridge, MA: Brookline Books.

SKarnulis, E. (1979). Support, not supplant, the natural home: Serving handicapped children and adults. In S. Maybanks \& M. Bryce (Eds.), Home-based services for children and families (pp. 64-76). Springfield, IL: Charles C. Thomas.
Surry, D. W., \& Gustafson, K. L. (1994). The role of perceptions in the adoption of computer-based learning (Report No. IR016832). East Lansing, MI: National Center for Research on Teacher Learning. (ERIC Document Reproduction Service No. ED 374 788)

WELLS, J., \& ANDERSON, D. (1997). Learners in a telecommunications course: Adoption, diffusion, and stages of concern. Journal of Research on Computing in Education, 30, 83-105.

WhiteHEAd, T. (1998). Report to the Missouri Planning Council for Developmental Disabilities. Unpublished manuscript, University of Missouri, Kansas City, Institute for Human Development.

\section{NOTES}

1. CAST is the Center for Applied Special Technology, 39 Cross Street, Suite 201, Peabody, MA 01960, (978) 531-8555 [http://www.cast.org].

2. Disability Access Resources (1998). Designing Web pages for people with disabilities [On-line]. Available: http://newmedia.com/ NewMedia/98/07/fastforward/disabled.html

3. World-Wide Web Consortium Web Accessibility Initiative is available on line at http://www.w3.org/WAI/

4. Callers may use the following numbers to reach the Missouri Developmental Disabilities Resource Center staff: 1-800-444-0821 or 1-800452-1195 TDD from 8:00 a.m.-5:00 p.m., Monday through Friday.

(Manuscript received November 24, 1998; revision accepted for publication February 1, 1999.) 